\title{
Dispositional Factors Among Youth: An Examination of their Relationship to Academic Achievement in a Collectivistic Tight Culture
}

\author{
Ramzi Nasser ${ }^{1}$, Lakshmi Narayanan ${ }^{2}$, Rim Chakraoui $^{3}$ \\ ${ }^{1}$ Lusail University, Doha Qatar \\ ${ }^{2}$ University of North Florida, Florida USA \\ ${ }^{3}$ Lusail University, Doha Qatar \\ ${ }^{1}$ ramzinaimnasser@hotmail.com or rnasser@lu.edu.qa
}

\begin{abstract}
With globalization and increasing interdependence between countries, cross-cultural differences between collectivistic and individualistic cultures have become a topic of increasing interest. In this study we examine the predictive validity of dispositional factors in a cross-cultural context. Three dispositional factors: Emotional Intelligence, Locus of Control and Self-Esteem were examined in the collectivistic and socially oriented culture of Oman. This study statistically assessed the prediction power of the three dispositional factors on academic achievement. A sample of 545 university students from a private university in Oman were surveyed. The findings show a strong correlation between Self-Esteem variables and grade point average. A significant finding in our study was that Self-Esteem was negatively related to achievement. The interpretation of the negative relation suggests that in tight cultures, individuals may negatively self-rate their Self-Esteem to compensate for the high achievement in their collective social context. This study has several important implications for future research in understanding the dynamics and predictability of personality and disposition in a collectivistic culture
\end{abstract}

Keywords

Emotional Intelligence, Locus of Control, Self-Esteem, university students, goals, achievement, social and cross-cultural psychology, collectivistic cultures

Article Received: 10 August 2020, Revised: 25 October 2020, Accepted: 18 November 2020

\section{Introduction}

Geert Hofstede defines culture as the collective programming of the mind which distinguishes members of one human group from another ${ }^{1}$ He posited the well-known structural-culture dimension theory ${ }^{2,3,4}$ which differentiated cultures based on notions such as individualism and collectivism, power-distance and uncertainty avoidance. Gefland $^{5}$ looked at data from 33 nations, they found many different characteristics that distinguish collective and individualistic cultures, variations could be mediated by tight and loose cultures. Cultures that are tight have strong norms and do not tolerate much deviance from expected behaviors. Loose cultures have weaker social norms and tolerate what is outside of the social norms. This notion of looseness and tightness can also be understood in terms of social psychological concepts such as "situational strength" . According to this perspective, there are strong and weak situations in the social system. Personality will be less of a predictor in strong situations or tight cultures and more of a predictor of behavior when the situations or the social systems are generally loosened. This point of view has also been reinforced by other cross-cultural researchers who have done work on personality and other dispositional factors. For example, researchers on cultural psychology such as Markus and Kitayama $(1998)^{7}$ point out that the dispositions and traits across cultures are debatable e.g., people from Eastern cultures may be more fatalistic when faced with negative events and their consequences; they may accept those negative outcomes which they have no ability to control. People who are similar in their dispositions being very high on sociability may behave quite differently depending on whether they belong to a tight or loose culture. The self and personality therefore may be socially constructed and may be contextual to a specific culture. This differentiation of tightness and looseness of cultures can help us better understand the dispositional factors among different cultures.

It is conceivable, then, to expect that the predictive validity of dispositions and traits may be different when collectivistic and tight cultures are compared to individualistic and loose cultures. It might be reasonable to also expect that in a strong collectivistic culture, there will be a high social dependence on the collective. This is what we call situational strength in a social system where individual personality may be less predictive of behavior because of the collective bonds of society ${ }^{8}$.

\section{The Present Study}

In the present study we attempt to examine the dispositional factors on predicting college student outcomes. The study context was in the Middle East, in a culture that is very collective, cohesive, and tight. We looked at three dispositional factors that have been frequently examined among college students in many Western cultures such as in North America, where the culture is very individualistic and "loose" compared to that of Middle Eastern cultures.

Three dispositional factors were examined to understand how they relate to academic achievement: Emotional Intelligence, Locus of Control, and Self-Esteem. These are constructs that have been well-researched, validated, and are discussed in detail below.

In a well-known study, Astin (1993) ${ }^{9}$ found, that how students do in college is impacted by interactions they have with peers and faculty. He stated that the amount of effort 
that students exerted socially and academically in their university experience was related to their academic success. Many studies have also been done helping to understand how different people from around the world deal with goal achievement and goal orientation. These studies suggest that the socialization process in society and schools often determines, to some extent, students' disposition to achieve $e^{7,10,11,12,13}$. In this study, we conceptualize goal achievement as academic achievement for a group of college students, and we examine the relationship of personality dispositional factors on school achievement.

Therefore, the primary purpose of our study is to bring together the psychological and educational knowledge to increase the understanding of the relative perceived psychological and social constructs on college success in a collectivistic culture such as Oman. We call these factors non-academic because they are not study behaviors as attendance, hours of study, or time management which can be termed "academic". Three non-academic factors, Emotional Intelligence, Locus of Control and Self-Esteem, and their relationship to academic achievement in college was examined. We look at these factors in the sections below.

\section{Emotional Intelligence}

Emotional Intelligence is a construct describing a person's ability to function effectively in the world and the ability to strongly feel another living thing's pain or joy ${ }^{14}$. Emotional Intelligence is different from IQ, which is the traditional measure of intelligence, focuses on cognitive abilities and mental capacities as in learning and recalling. Emotional intelligence consists of basic life skills that help people control impulses, self-determination, persistence, motivation, and understanding how others feel.

Many early studies point to the role of Emotional Intelligence in achievement. Petrides et al $(2004 ; 2007)^{15,16}$ research used Emotional Intelligence scales to validate and examine the predictability of Emotional Intelligence on achievement for different age groups. They found that among British students, trait Emotional Intelligence moderated the relationship between cognitive ability and academics. Parker et al. (2004; 2005) ${ }^{17,18}$ also found that academic success was associated with several dimensions of Emotional Intelligence. Parker's study found that students' academic success was significantly related to higher levels of social and emotional competencies and higher success in transitioning from high school to university. Sparkman et al. $(2012)^{19}$ examined college success in a sample of undergraduate students. They found a significant relationship between non-academic factors of Emotional Intelligence and college success. However, few studies have examined how the predictive power of Emotional Intelligence can be moderated or influenced by the situational strength or the tightness or looseness within a specific culture. Fewer studies have looked at the nonacademic factors related to college students' achievement.

\section{Self-Esteem}

Self-Esteem has been a topic of interest for many decades and has been studied extensively in the United States. Self-
Esteem is the evaluative component of the self-concept; it describes a person's overall sense of self-worth or personal value $^{20}$. One major area of research has been the examination of how Self-Esteem is related to academic achievement. Several researchers have identified academic achievement as an important determinant of Self-Esteem. For example, Harter (1985) ${ }^{21}$ believed that self-perceived competence in schooling is a major factor that individuals use to assess their own Self-Esteem. In fact, many studies have found that there is a positive relationship between SelfEsteem and academic achievement ${ }^{22,23}$. Thus, it could be inferred that the higher the achievement, the higher the SelfEsteem. There is also some disagreement regarding the nature of this relationship. While some researchers believe that students' higher academic performance fosters higher Self-Esteem, other researchers state that positive SelfEsteem is a necessary condition for academic achievement. Purkey $(1970)^{24}$ believes there is a reciprocal relationship between Self-Esteem and academic achievement, one or the other fosters positive change.

\section{Self-Esteem and Culture}

Self-Esteem has been reported as a significant factor to goal achievement in individualistic cultures like the American culture $^{20,25}$. This preoccupation with Self-Esteem can also be seen in the volumes of scholarly research and writings on the topic. Schools across the United States have implemented hundreds of programs to boost students' SelfEsteem and to increase achievement. Singelis et al (1999); Schmitt and Allik, (2005) in their examination of SelfEsteem in 53 countries found significant differences in culturally specific features of global Self-Esteem.

Many researchers have found that individuals from collectivistic cultures have much stronger independent views of the self. Individuals from collective cultures feel that behaviors are strongly dependent on and controlled, to a large extent, by the others in the environment. In contrast, those from individualistic cultures feel they have a high degree of behavioral control and, thus, can contour their success and achievements discounting social or environmental pressures or norms.

Evidence of cross-cultural differences on Self-Esteem strongly suggests that Self-Esteem is related to cultural values and is a cultural phenomenon rather than a universal human need. A growing body of evidence, particularly from Japan, suggests powerful cultural differences in the importance of Self-Esteem ${ }^{25}$. For example, in a collectivist culture like that of Japan, Heine et al. (1999) ${ }^{25}$ suggest that people are focused on relationships and connections with others, rather than standing out; they are more disposed to humility and collective achievement. In contrast, in Western cultures, North Americans, tend to self-assess their worth or value and not discount inherited traits, but act in demonstrating and proving their worth and making SelfEsteem as a highly desired personality trait. Some researchers have suggested that the pursuit of Self-Esteem can sometimes interfere with learning and mastery ${ }^{26,27,28}$. When people have self-validation goals, small mistakes, failures, and negative feedback may become self-threats rather than opportunities from which to learn and improve. 
There are many on-going debates on Self-Esteem as it is valued in many cultures and pointed out by Konrath $(2012)^{29}$. People from individualistic cultures, such as that of North America, focus on one's own uniqueness and independence and will report higher scores on Self-Esteem when compared to more collectivistic cultures. Individualistic cultures may even tend to enhance their perception of their Self-Esteem. In contrast, collectivistic cultures may give more importance to self-criticism and have a sense of interdependence rather than enhancing individual Self-Esteem.

\section{Locus of Control}

Locus of Control refers to one's belief in his or her abilities to control life events ${ }^{30}$. Ever since Rotter (1966) ${ }^{31}$ came up with the concept of Locus of Control, there have been several decades of research drawing on the relationship between Locus of Control and culture. Some of the research clearly suggests that there are significant differences between Eastern and Western cultures on the perception of control. Researchers have found that collective societies such as Japan or India exhibit more external Locus of Control compared to more individualistic cultures such as the United States or Canada ${ }^{32,33}$. It is conceivable that more collectivistic cultures develop secondary control because they are socialized to suppress personal control as compared to more individualistic cultures where there is primacy to control. This could explain some of the significant differences between externality and internality across cultures as shown by several studies ${ }^{34,35,36}$. In a large-scale study done by Gifford et al., $(2006)^{37}$, they examined Locus of Control in the context of first-year students entering university. They found that internals obtained significantly higher GPA's than externals. However, most of the studies have been done in Western, individualistic cultures and it is conceivable that culture could be an important moderator between internality, externality, and academic achievement.

\section{Academic Achievement}

A plethora of studies have examined postsecondary student success, among them is Pascarella and Terenzini's (1991) ${ }^{38}$ review of many studies coverings two decades of research that addressed the college change process. The review of these studies has focused on cognitive and non-cognitive factors and how they impact achievement. Messick (1979) ${ }^{39}$ suggests that these factors include dispositional behaviors including self-concepts such as self-efficacy beliefs, outcome expectancies, meta-cognitive knowledge, and performance goals leading to possible achievement ${ }^{40,41,42}$.

To summarize, we will examine how three dispositional factors of Emotional Intelligence, Self-Esteem and Locus of Control predict college success in a sample of undergraduate students in a very collectivistic and tight culture. We expect that the predictive power of these factors will be quite different from those studies done in individualistic-loose cultures, and the pattern of relationships may be different from what has been found from traditional studies done in Western cultures. A limitation in this study is that we do not compare our sample to a Western pairable sample that we could compare cross-culturally and bring new evidence in the literature on individualistic and collectivist cultures.

We will examine the following research questions:

1. What is the relation between and among the three dispositional factors and academic achievement?

2. Which dispositional factor is the strongest predictor of academic achievement?

3. What elements of the dispositional factor significantly predict achievement?

\section{Methods}

\section{Participants}

There were 570 students sampled in this study. We removed outliers and missing values and outliers for the independent variables. We performed the correlation and regression analysis and removed missing values and outliers for the GPA which further reduced our data to $n=545$ students. Students were selected taking a university requirement course essential to complete other majors at the university in the College of Arts and Applied Sciences in a medium-sized 4-year university in the Southeastern parts of Oman. The university grants a baccalaureate and a master's degree. The highest proportion of students were female $\mathrm{n}=505$ and $\mathrm{n}=40$ males. Comparably to the university population, females had the highest proportion which came to $70 \%$.r The sample came from three colleges; $n=202$ students $(37.1 \%)$ from the College of Business and Commerce, $n=113,(20.7 \%)$ from the College of Arts and Applied Sciences and $n=190,(34.9 \%)$ from the College of Engineering (note, not all students responded to this item in the questionnaire). All the students were Omani, and the age population was at 20.4 years.

\section{Questionnaires}

Background information was obtained through demographic questions regarding gender, nationality, self-reported cumulative grade point average (on a $0-4$ point scale), and their majors. Students gave consent to check their GPA records through their university identification number written on the questionnaire.

For all dispositional factors, not all items were used for each of the factor measures of Emotional Intelligence, Locus of Control, and Self-Esteem. For the Self-Esteem items, we selected items from the scale that reflect operative allocentric items. I.e., rather than take the "I," they generally reflect themselves within the group to positively contribute as others. For the Locus of Control, we selected items tapping into non-individualistic- external Locus of Control items having fatalistic attributions. The reason was to see whether collectivist attributions in a collectivist culture will predict achievement. Lastly, for self-rated intelligence, we used six items for this questionnaire that dealt with selfregulative ability as to deal with their emotions. Two local academics, who were Omani and familiar with Omani culture, found that some of these scales were not appropriate or relevant for this study and so, only a few subsets of items were used.

Emotional Intelligence. This was measured through the Trait Emotional Intelligence Questionnaire (Petrides, 
$2009)^{43}$. All items were rated on a 5-point Likert scale. Items included: "I often find it difficult to see things from another person's viewpoint," "on the whole, I'm a highly motivated person," "I usually find it difficult to manage my emotions," "many times, I can't figure out what emotion I'm feeling," and "I'm usually able to find ways to control my emotions when I want to."

Self-Esteem. This was measured using the Rosenberg $(1965)^{44}$ Self-Esteem Scale. Three statements were used for the scale. All items were stated in the positive direction. For the Rosenberg Self-Esteem Scale, the items selected included: "I feel I have a number of good qualities," "I am able to do things as well as most other people" and "I certainly feel useful at times." Participants were asked to rate their agreement based on a five-point numerical rating scale ( $1=$ strongly disagree, $5=$ strongly agree). The three ratings on the score were averaged such that a high score would mean that students self-rated above average SelfEsteem.

The Locus of Control. This was measured using the Rotter $(1966)^{31} 13$-item Locus of Control Scale. The scale measures the degree of perceived and generalized expectancies for internal versus external control of reinforcement. Students were asked to rate on a five-point scale $(1=$ strongly disagree to $5=$ strongly agree $)$. We used 5 questions from this scale which included: "Many of the unhappy things in people's lives are partly due to bad luck," "I have often found that what is going to happen will happen," "people's misfortunes result from the mistakes they make," "in the long run people get the respect they deserve in this world," and "many times, exam questions tend to be so unrelated to course work that studying is really useless." The responses were averaged to get an aggregate score for internal/external Locus of Control. The greater the average score, the greater the external Locus of Control as opposed to an internal Locus of Control.

Grade Point Average. We obtained students cumulative grade point average (GPA) for the semester prior to the data collection on the questionnaire.

Table 1. Means and Standard Deviation for Each Item

\begin{tabular}{llll}
\hline & \multicolumn{3}{c}{$\begin{array}{l}\text { Item Means and Standard } \\
\text { Deviations for Each Item }\end{array}$} \\
\cline { 2 - 4 } Items & $N$ & Mean & SD \\
\hline $\begin{array}{l}\text { SE1. I feel that I have a number of good } \\
\text { qualities. }\end{array}$ & 544 & 4.51 & .579 \\
SE2. I am able to do things as well as most & 544 & 1.58 & .666 \\
$\begin{array}{l}\text { other people. } \\
\text { SE3. I certainly feel useful at times. }\end{array}$ & 544 & 2.52 & 1.058 \\
$\begin{array}{l}\text { LOC1. Many of the unhappy things in } \\
\text { people's lives are partly due to bad luck. }\end{array}$ & 545 & 2.53 & 2.53 \\
$\begin{array}{l}\text { LOC2. I have often found that what is going } \\
\text { to happen will happen. }\end{array}$ & 536 & 4.16 & 4.16 \\
$\begin{array}{l}\text { LOC3. People's misfortunes result from the } \\
\text { mistakes they make. }\end{array}$ & 545 & 3.52 & 3.52 \\
$\begin{array}{l}\text { LOC4. In the long runpeople get the respect } \\
\text { they deserve in this world. }\end{array}$ & 545 & 3.88 & 3.88 \\
$\begin{array}{l}\text { LOC5. Many times, exam questions tend to } \\
\text { be 50 unrelated to course work that studying }\end{array}$ & 545 & 2.81 & 2.81 \\
in really useless. & & & \\
$\begin{array}{l}\text { EQ1. I often find it difficult to see things } \\
\text { from another person's viewpoint. }\end{array}$ & 545 & 2.70 & 2.70 \\
$\begin{array}{l}\text { EQ2. On the whole, I'ma highly motivated } \\
\text { person. }\end{array}$ & 537 & 4.50 & 4.50 \\
$\begin{array}{l}\text { EQ3. I usually find it difficult to mange my } \\
\text { emotions. }\end{array}$ & 545 & 2.60 & 2.60 \\
$\begin{array}{l}\text { EQ4. Many times, I can't figure out what } \\
\text { emotion I'm feeling. }\end{array}$ & 545 & 2.58 & 2.58 \\
$\begin{array}{l}\text { EQ5. I'm usually able to find ways to } \\
\text { control my emotions when I want to. }\end{array}$ & 540 & 3.95 & 3.95 \\
$\begin{array}{l}\text { EQ7. I generally believe that things will } \\
\text { work out fine in my life. }\end{array}$ & 535 & 4.45 & 4.45 \\
\hline
\end{tabular}

\section{Procedure}

All the questionnaires were translated from English to Arabic using the following procedure: we used the committee translation method where a panel of experts translate from a source (English) to a target language (Arabic). If all the translations are the same, then the translation can be considered valid in the target language ${ }^{45}$ The committee was made up of two bilingual academics. Each translated the items and the scale directions independently, the translators being blind to one another's translation. The two blind translations were attempted then compared by a bilingual, which did not take part in the translation procedure. To check the convergence of the translations in case of disagreement, the three met and decided the change by consensus.

\section{Results}

We initially removed all missing and anomalous data by examining the distribution and kurtosis of the independent variables. We had removed some of the outliers based on the distributions of the data. We specifically looked at outliers that went in both directions; those average values at the extremes, falling below the first quartile and beyond the third quartile of the distribution. Those extreme outliers corresponding to those cases were removed from the analysis. Thus, the total sample came to 545 students.

The rating on each of the items pertinent to each dimension, was added and divided by the number of items which formed an aggregate score per dimension: this was the average score per item. Each of the dimension's average was then used as a measure of that dimension. We also obtained a standard deviation on each of the items. The means and standard deviations are reported on Table 1. Those negative or opposite directional items were then recoded to reflect the positive direction of the meaning of the items.

The reliability analysis (Cronbach alpha) of Emotional Intelligence dimension $(\alpha=0.24)$, Locus of Control dimension $(\alpha=0.58)$, and Self-Efficacy dimension $(\alpha=-0.31)$, were impartial, particularly that not all the items were used from the original questionnaire and may have caused the loss of the psychometric properties of these instruments in their current form. The negative reliability suggests that negative directed items where present in the scale. We recoded the items for the regression analysis by inverting the negative item responses.

Generally, students had a reasonable Self-Esteem of $M=2.87, S D=43$; they had a greater level of External Locus Control, as the average level of the measure was above the median score of " 3 " $(M=3.38, S D=0.58)$. We also obtained a measure of the average score of emotional intelligence $M=3.45, S D=0.55$, which came to above the middle-neutral value of " 3 " which was neither positive nor negative " 3 ." In Table 2, the correlation analysis showed a weak correlation between the three dispositional factors and cumulative GPA. A negative and significant correlation was found between the factors: Emotional Intelligence and Self-Esteem; Emotional Intelligence and Locus of Control and Self-Esteem and cumulative GPA. With weak 
correlations between the dimensions representing the items, we were more intent on looking at each individual item of the predictor(s) dimension.

Table 2. Correlation Between Each Dimension

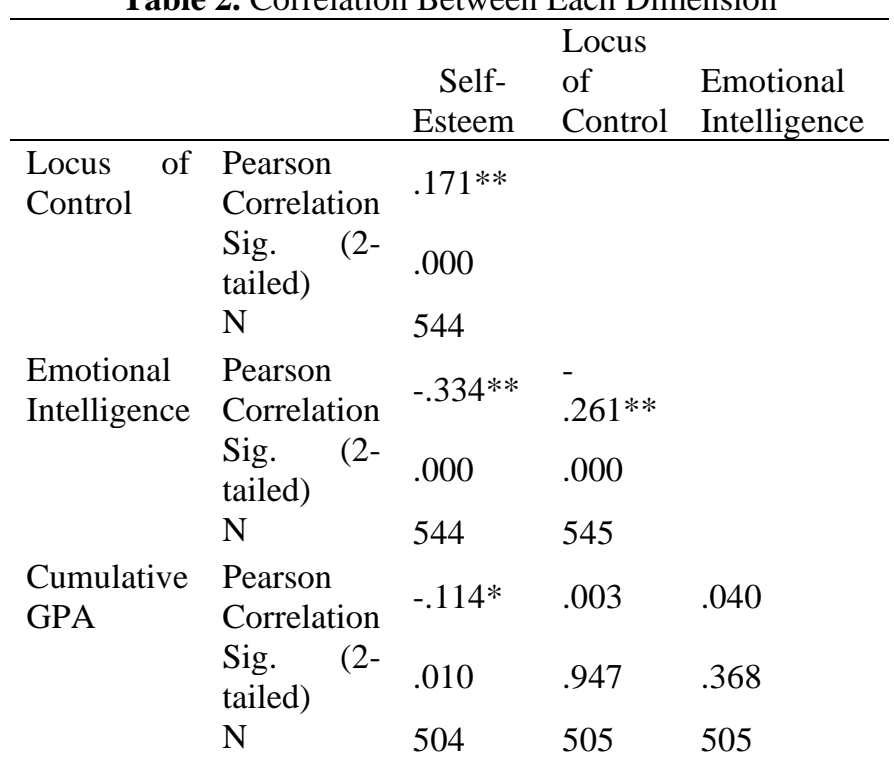

** Correlation is significant at the 0.01 level (2-tailed).

* Correlation is significant at the 0.05 level (2-tailed).

We attempted a stepwise regression analysis to examine the joint contributions of Self-Esteem, Locus of Control and Emotional Intelligence on achievement scores (grade point average). The purpose of using such an analysis was to find the relation between dispositional factors and whether they can predict achievement. The selection of the variables (factor items) of dispositional factors suggests students being able to deal with life events and learning experiences and how that might provide a greater sense of goals, aspiration, and student motivation to achieve.

The reason for using of stepwise regression was to find which variables in the regression equation have a robust and significant prediction power on the dependent variables. The stepwise regression examined the largest correlation between the independent and dependent variables and placed it in the regression equation and then recursively selected the next highest significant predictor controlling the variance in the preceding step of the regression until all significant predictors were exhausted.

In the first regression, we ran the three factors of SelfEsteem, Locus of Control and Emotional Intelligence on grade point average. The independent factor of Self-Esteem was the main predictor entered in the regression with a significant beta coefficient. The resulting model from the analysis explained $5 \%\left(R^{2}=0.05\right)$ of the variance. The model was significant to the extent the independent variables predicted the dependent variables with the F-ratio $F(2,475)=13.28, p=0.00$. In terms of the adequacy of the model, it did not exceed the tolerance levels (See Table 3 and Table 4). As Self-Esteem was the main predictor, we carried another set of regression analysis to determine the predictive power of each item composing the Self-Esteem dimension.

To answer the third research question, and recognizing the main predictor of Self-Esteem, we ran a second regression using Self-Esteem items on the self-reported grade point average. The beta coefficients for the first item, "I have a number of good qualities," was a significant predictor with a t-test value of $t(503)=-5.14, p=0.00$ and "I am able to do things as well as most other people" had a t-test value of $t(503)=-2.05, p=0.00$. In both cases there was a negative relation suggesting that the decreased Self-Esteem strongly predicted high achievement.

Table 3. Regression Using the Self-Esteem, Locus of Control on Achievement

\begin{tabular}{lcclll} 
& \multicolumn{2}{c}{ Stand. } & & & \\
& & \multicolumn{1}{c}{$\mathrm{T}$} & $\mathrm{R}^{2}$ & $\Delta \mathrm{R}^{2}$ & $\mathrm{~F}$ \\
\cline { 2 - 6 } $\begin{array}{l}\text { Self- } \\
\text { Esteem }\end{array}$ & -.143 & $-2.9^{* *}$ & 0.05 & $.021^{*}$ & $2.93^{* *}$ \\
$\begin{array}{l}\text { Locus of } \\
\text { Control } \\
\text { Emotional }\end{array}$ & .031 & .68 & & & \\
Intelligence & .035 & .712 & & & \\
\hline
\end{tabular}

\section{Discussion}

In this study we investigated the relation between three dispositional factors of Locus of Control, Emotional Intelligence, Self-Esteem, and academic achievement. The research investigated three dispositional factors in relation to achievement. More specifically, we were interested in how these three psychological factors predict academic success in a very collectivistic and tight culture such as Oman.

Table 4. Regression Using the Self-Esteem Variables on

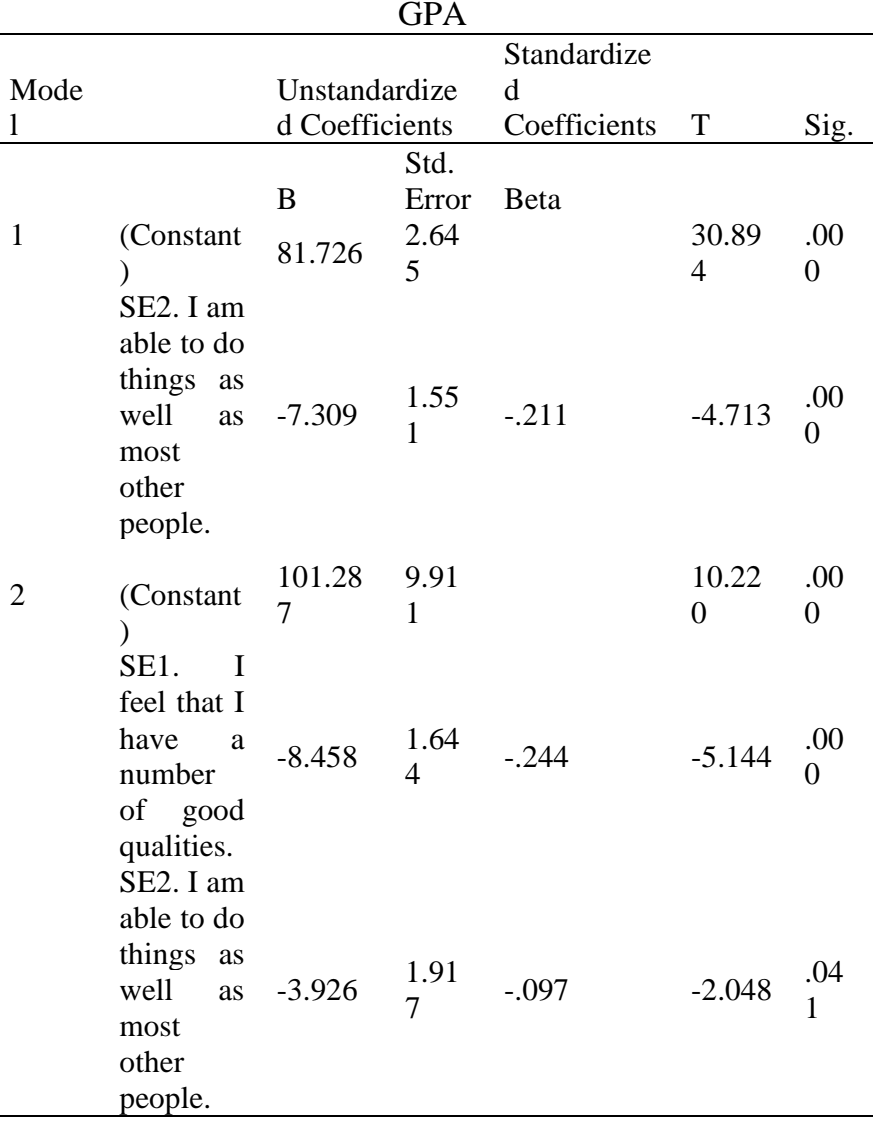

Some significant findings emerged. First, it does appear that Self-Esteem is predictive of college success, but a negative relationship emerged. This means that individuals with lower Self-Esteem seemed to do better in college than those with higher Self-Esteem. One could interpret, as a 
possibility, that in a strong collectivistic culture with high interdependence and extended social networks, a high SelfEsteem may be being vain, as a social asset but not as an academic one. Indeed, however, college students with a stronger individualistic disposition think critically of themselves and, thus, are more likely to have higher levels of perceived academic achievement. Some of these findings are consistent with previous research on Self-Esteem (Schmitt, \& Allik, 2005).

The fact that both Emotional Intelligence and Locus of Control are weak predictors could support the notion that in tight-collective cultures, individuals may suppress their own dispositions, whether external or internal locus of control, and thus personality will be less of a predictor in strong situations or in tight cultures. The findings support our discussion that lower statistical predictive value of traits and dispositions in collectivistic cultures.

The three dispositional factors were also seen to reflect a level perceived academic control in what we saw as indirectly impacting academic achievement. Perceived academic control as Locus of Control and Emotional Intelligence dispositions were much weaker than SelfEsteem in predicting achievement. Each of these effects are comparable to those obtained in earlier studies in which academic achievement was directly linked with perceived academic control ${ }^{46,47}$, and to a lesser degree, the higher ordered thinking ${ }^{48}$. Therefore, the results of this study, specifically regarding Self-Esteem, draw further attention as a key psychosocial construct for college students' academic achievement and success and bring into light the direct impact of the disposition on students' academic success.

Moreover, with the existing higher educational systems in Oman not matching the pattern of organization and operations of the tribal Omani society, students may find it difficult to embrace higher education systems or other organizations with a strong individualistic culture. Oman is a largely collectivist society where students have little sense of individual achievement and individual effort. Rather, there is more stress on the collective and collective achievement and honor. Omani society, in its organizational structure, may not be aligned with modern day institutions, higher education structures, hierarchies, individual achievement, and levels of control. Many of the students offset their Self-Esteem, knowing the significance of strong achievement, they may lower their Self-Esteem rating as to bring them honor and value in their circle or collective. Given also that Oman is largely a segregated society where women experience their own public spaces and rarely do tread into the spaces of men, and conversely for men. Also, given the patriarchal nature of the tribal society in the Arab Gulf, it would be inconceivable for singular women to standout in a largely male-dominated tribal structure, women struggles are limited to the family context or in their own small circles. Women understand this structure and reinforce it for various reasons, among them: it protects women's honor, pride, virtue, safety, and most importantly, livelihood. Women may forfeit self-esteem, even to some relative extent their individuality, to show devotion to the collective. At the same time, they want to achieve and impute that devotion for the family and community (i.e., tribe). London $(1992)^{49}$ pointed out that in first generation students, family plays an important role in the development of their educational and social identities. Bui $(2002)^{50}$ also found that first-generation students attended college not only for themselves, but to bring honor to their families. This is a crucial point in a collectivistic culture such as Oman. In some cases, students want to remain part of the family but also want to adapt to the culture of university life; sometimes they need to break away from the traditional demands to have an internal locus- in a tight culture such as Oman, this can be very challenging for students. Conclusively, the negative association of Self-Esteem and achievement could be because of the cultural expectations as discussed earlier. It is possible that the high achievement associated with negative Self-Esteem is indicative of their own humility within a group as not to stand out, but to melt in the group- compensating their own esteem. This draws them to work harder and improve on their social status through achieving higher in their educational endeavor.

\section{Conclusion, Limitations, And Future Directions}

Our study is unique in that we examined the role of personality disposition in a unique cultural context, in a closed, tight, and collectivistic culture that has not been examined before. Although there has been extensive research and a plethora of studies supporting factors that predict academic achievement, our study brings out the importance of the situational strength of a closed, tight culture that supersedes the predictive power of dispositional factors.

The results from this study have important implications for researchers who examine the role of personality and other dispositional factors in predicting behavior in collectivistic cultures that are tight. As Triandis $(1977)^{51}$ has pointed out, personality is less predictive in collectivistic cultures, and the situation or social context may be the powerful determinant of behavior. We must be cautious in making assumptions about the universality of personality and dispositions across cultures. While students in Oman might be disposed to contextual factors as in place, time, role, occasion, and situation ${ }^{52}$ many of the Omani students see themselves within the group, having a social and contextual self-concept referencing and are prone to strictly conform to group norms. Omani students in Western environments may see the context differently and could easily dispose of the collective behavior. However, within their own groups and environment, the greater the collective tightness, the lower the centeredness around the self and the greater the tendency and need to locate oneself in the group. Also, the low SelfEsteem can be interpreted from within an etic perspective. Students in Oman draw on their low Self-Esteem as a mechanism to fit in and be a part of the group, conceptualizing the self in relation to the social context is one way of defining the self within the group. They may even see themselves in terms of the group with whom they share common values and beliefs. As Triandis, Chan, Bhawuk, Iwao, \& Sinha $(1995)^{53}$ state, people from a collectivist culture draw on the allocentric self-concepts more than those from individualistic cultures, so they may provide the following sense of self as: "others see me as a gentle person" or the item of the Self-Esteem which had a significant predictive power on achievement: "I am able to do things as well as most other people." What are the 
implications of these findings to educators? Certainly, educators' knowledge of cross-cultural and specific cultural dispositions may impact in the way they design curriculum, deliver, and more importantly assess their students. In the context of Oman, much more is needed in the way the curriculum is delivered and attained. Educators need to engage students in group activities, collaborative learning and thus build esteem and motivation and directly link to collective achievement.

This study had several limitations, only a small cross-section of students was examined, this was done only in one region of Oman. We would have liked also to assess a Western sample using the same sub-items to compare the findings and provide validity to the interpretations made in this study. Furthermore, only a few items from the scales were used, rather than the full scale which may have caused the loss of the psychometric properties of the scale. Yet, we feel that even with these subsets of items, our conjectures were supported by the results.

Much of the sample were women, so it is possible that our results could have been different if we had more men in the sample. Future research can examine if these patterns of relationships between Self-Esteem, Emotional Intelligence, Locus of Control, and academic success in collectivistic cultures, is moderated by gender. Also, there are many other dimensions such as other dispositional factors like proactivity, optimism, and other variables, related to academic success, that were not examined. Future studies should use other populations and examine other regions in Oman, with other dimensions in addition to those examined in this study. We know that many of the Arab countries, as in the Gulf, have adopted an urban lifestyle in major cosmopolitan areas like Dubai and Abu Dhabi in in the United Arab Emirates, in Doha in Qatar, Kuwait City in Kuwait, and Manama in Bahrain. They have transformed sedentary lives into mostly city dwelling states, disrupting the tribal system's traditional societal structures and the underpinnings of the collective. Our sample is unique because of Oman being a geographically mountainous region, with a population spread across the country and with a diverse makeup in terms of religious sects and languages. Our sample was situated in rural, sedentary, and mostly traditional groups that maintained those characteristics of patriarchal, collectivistic, and tight cultures. With regard to Self-Esteem, some researchers have suggested that there is a difference between personal Self-Esteem and collective Self-Esteem, and implicit and explicit Self-Esteem ${ }^{29}$. Future research, specifically on collectivistic cultures should examine the role of these dimensions in relation to achievement.

\section{References}

[1] Hofstede, G. (2007). Asian management in the 21st century. Asia Pacific Journal of Management, 24(4), 411-420.

[2] Hofstede, G. (1984). Culture's consequences: International differences in work-related values. Beverly Hills, USA: Sage Publications.

[3] Hofstede, G., Hofstede, G. J., \& Minkov, M. (1991). Cultures and organizations: Software of the mind. London, England: McGraw-Hill.

[4] Hofstede, G. J., Pedersen, P., \& Hofstede, G. H. (2002). Exploring culture: Exercises, stories and synthetic cultures. Yarmouth, USA: Intercultural Press.

[5] Gelfand, M. J., Raver, J. L., Nishii, L., Leslie, L. M., Lun, J., Lim, B. C., \& Aycan, Z. (2011). Differences between tight and loose cultures: A 33-nation study. Science, 332(6033), 1100-1104.

[6] Mischel, W. (2013). Personality and assessment. New Jersey, USA: Lawrence Erlbaum.

DOI: https://doi.org/10.4324/9780203763643

[7] Markus, H. R., \& Kitayama, S. (1998). The cultural psychology of personality. Journal of Cross-Cultural Psychology, 29(1), 63-87. DOI: $10.1177 / 0022022198291004$

[8] Mischel, W. (1977). On the future of personality measurement. American Psychologist, 32(4), 246-254

[9] Astin, A.W. (1993). What Matters in College? Four Critical Years Revisited. San Francisco: USA: Jossey-Bass.

[10] Dweck, C. S. (1986). Motivational processes affecting learning. American Psychologist, 41(10), 1040-1048.

[11] Kythreotis, A., Pashiardis, P., \& Kyriakides, L. (2010). The Influence of School Leadership Styles and Culture on Students' Achievement in Cyprus Primary Schools. Journal of Educational Administration, 48(2), 218-240. DOI 10.1108/09578231011027860

[12] Tao, V. Y. K., \& Hong, Y. Y. (2014). When academic achievement is an obligation: Perspectives from social oriented motivation. Journal of Crosscultural Psychology, 45, 110-136. DOI: 10.1177/0022022113490072. 
[13] Yu, A.-B., \& Yang, K.-S. (1994). The nature of achievement motivation in collectivist societies. In U. Kim, H. C. Triandis, Ç. Kâğitçibaşi, S.-C. Choi, \& G. Yoon (Eds.), Cross-cultural research and methodology series, Vol. 18. Individualism and collectivism: Theory, method, and applications (pp. 239-266). Thousand Oaks, CA, US: Sage Publications, Inc.

[14] Goleman, D. (1995). Emotional intelligence. New York: Bantam Books.

[15] Petrides, K. V., Frederickson, N., \& Furnham, A. (2004). The role of trait emotional intelligence in academic performance and deviant behavior at school. Personality and Individual Differences, 36(2), 277-293. DOI;10.1016/S0191-8869(03)00084-9

[16] Petrides, K. V., Pita, R., \& Kokkinaki, F. (2007). The location of trait emotional intelligence in personality factor space. British Journal of Psychology, 98(2), 273289.

[17] Parker, J. D., Summerfeldt, L. J., Hogan, M. J., \& Majeski, S. A. (2004). Emotional intelligence and academic success: Examining the transition from high school to university. Personality and Individual Differences, 36(1), 163-172. DOI: 10.1016/S0191-8869(03)00076-X

[18] Parker, J., Duffy, J., Wood, L., Bond, B., \& Hogan, M. (2005). Academic achievement and emotional intelligence: Predicting the successful transition from high school to university. Journal of The First-Year Experience \& Students in Transition, 17(1), 67-78.

[19] Sparkman, L., Maulding, W., \& Roberts, J. (2012). Non-cognitive predictors of student success in college. College Student Journal, 46(3), 642-652.

[20] Baumeister, R. F., Campbell, J. D., Krueger, J. I., \& Vohs, K. D. (2003). Does high Self-Esteem cause better performance, interpersonal success, happiness, or healthier life styles?. Psychological Science in The Public
Interest, 4(1), 1-44. DOI:10.1111/15291006.01431

[21] Harter, S. (1985). Competence as a dimension of self-evaluation: Toward a comprehensive model of self-worth. In Leahy, R. (ed.) The Development of the Self, New York, USA: Academic Press.

[22] Bankston, C. L., \& Zhou, M. (2002). Social capital and immigrant children's achievement. Schooling and Social Capital in Diverse Cultures, 13(1), 13-39. DOI: $10.1108 / \mathrm{S} 1479$ -

$3539 \% 282002 \% 290000013002$

[23] Schmidt, J. A., \& Padilla, B. (2003). SelfEsteem and family challenge: An investigation of their effects on achievement. Journal of Youth and Adolescence, 32(1), 37-46. DOI: 10.1023/A: 1021080323230

[24] Purkey, W. W. (1970). Self-concept and school achievement. Englewood-Cliffs, USA.: Prentice-Hall, Inc.

[25] Heine, S. J., Lehman, D. R., Markus, H. R., \& Kitayama, S. (1999). Is there a universal need for positive self-regard?. Psychological Review, 106(4), 766-794. DOI: 10.1037/0033-295X.106.4.766

[26] Covington, M. V. (1984). The self-worth theory of achievement motivation: Findings and implications. The Elementary School Journal, 85(1), 5-20. DOI: 10.1086/461388? journalCode $=$ esj

[27] Deci, E., L., and Ryan, R. (2000). "The" what" and" why" of goal pursuits: Human needs and the self-determination of behavior. Psychological Inquiry, 11(4), 227-268.

DOI:10.1207/S15327965PLI1104_01

[28] Dweck, C. S. (2000). Self-theories: Their role in motivation, personality, and development. Philadelphia, USA: Psychology Press.

[29] Konrath, S. H. (2014). Self-Esteem, culturally defined. In Cultural Sociology of Mental Illness: An A-to-Z Guide. Thousand Oaks. USA: Sage Publications. 
[30] Strauser, D. R., Ketz, K., \& Keim, J. (2002). The relationship between selfefficacy, Locus of Control and work personality. Journal of Rehabilitation, 68(1), 20-26.

[31] Rotter, J. B. (1966). Generalized expectancies for internal versus external control of reinforcement. Psychological Monographs: General and Applied, 80(1), 1-28. DOI: $10.1037 / \mathrm{h} 0092976$

[32] Narayanan, L., Menon, S., \& Spector, P. (1999). A cross-cultural comparison of job stressors and reactions among employees holding comparable jobs in two countries. International Journal of Stress Management, 6(3), 197-212. DOI: https://doi.org/10.1023/A:1021986709317

[33] Siu, O. L., Spector, P. E., Cooper, C. L., Lu, L., \& Yu, S. (2002). Managerial stress in greater China: The direct and moderator effects of coping strategies and work Locus of Control. Applied Psychology, 51(4), 608-632. DOI: 10.1111/14640597.00111

[34] Dille, B., \& Mezack, M. (1991). Identifying predictors of high risk among community college telecourse students. American Journal of Distance Education, 5(1), 24-35.DOI: $10.1080 / 08923649109526729$

[35] Janssen, T., \& Carton, J. S. (1999). The effects of Locus of Control and task difficulty on procrastination. The Journal of Genetic Psychology, 160(4), 436-442. DOI: $10.1080 / 00221329909595557$

[36] Njus, D. M., \& Brockway, J. H. (1999). Perceptions of competence and Locus of Control for positive and negative outcomes: predicting depression and adjustment to college. Personality and Individual Differences, 26(3), 531-548. DOI: 10.1016/S0191-8869(98)00169-X

[37] Gifford, D. D., Briceno-Perriott, J., \& Mianzo, F. (2006). Locus of Control: Academic Achievement and Retention in a Sample of University First-Year Students. Journal of College Admission, 191, 18-25.
[38] Pascarella, E. T., \& Terenzini, P. T. (1991). How college aflects students. Findings and Insights from Twenty Years of Research. San Francisco, USA: JosseyBass. DOI: 10.1007/BF00992835

[39] Messick, S. (1979). Potential uses of noncognitive measurement in education. Journal of Educational Psychology, 71(3), 281.

[40] Harackiewicz, J. M., Barron, K. E., Pintrich, P. R., Elliot, A. J., \& Thrash, T. M. (2002). Revision of achievement goal theory: Necessary and illuminating. Journal of Educational Psychology, 94(3), 638-645. DOI: $\quad 10.1037 / 0022$ 0663.94.3.638

[41] Bazelais, P., Lemay, D. J., \& Doleck, T. (2016). How Does Grit Impact College Students' Academic Achievement in Science? European Journal of Science and Mathematics Education, 4(1), 33-43.

[42] Wibrowski, C. R., Matthews, W. K., \& Kitsantas, A. (2017). The role of a skills learning support program on firstgeneration college students' selfregulation, motivation, and academic achievement: A longitudinal study. Journal of College Student Retention: Research, Theory \& Practice, 19(3), 317-332.DOI: $10.1177 / 1521025116629152$

[43] Petrides, K. V. (2009). Technical manual for the Trait Emotional Intelligence Questionnaires (TEIQue). London, England: London Psychometric Laboratory.

[44] Rosenberg, M. (1965). Society and the adolescent self-image. Princeton, USA: Princeton University Press.

[45] Nasser, R. (2005). A method for social scientists to adapt instruments from one culture to another: The case of the Job Descriptive Index. Journal of social sciences, 1(4), 232-237. https://doi.org/10.3844/jssp.2005.232.237

[46] Perry, R. P., Hladkyj, S., Pekrun, R. H., \& Pelletier, S. T. (2001). Academic control and action control in the achievement of college students: A longitudinal field 
study. Journal of Educational Psychology, 93(4), 776-

789.https://doi.org/10.1037/0022-

0663.93.4.776

[47] Ruthig, J. C., Perry, R. P., Hladkyj, S., Hall, N. C., Pekrun, R., \& Chipperfield, J. G. (2008). Perceived control and emotions: Interactive effects on performance in achievement settings. Social Psychology of Education, 11(2), 161-180. DOI: 10.1007/s11218-007-9040-0

[48] Giancarlo, C. A., \& Facione, P. A. (2001). A look across four years at the disposition toward critical thinking among undergraduate students. The Journal of General Education, 50(1), 29-55. DOI:10.1353/jge.2001.0004

[49] London, H. B. (1992). Transformations: Cultural challenges faced by first-generation students. New Directions for Community Colleges, 80, 5-11.

[50] Bui, K. V. T. (2002). First-generation college students at a four-year university: Background characteristics, reasons for pursuing higher education, and first-year experiences. College Student Journal, 36(1), 3-12.

[51] Triandis, H. C. (1977). Cross-cultural social and personality psychology. Personality and Social Psychology Bulletin, 3(2), 143-158. DOI: 10.1177/014616727700300202

[52] Shweder, R.A., \& Bourne, E.J. (Eds.) (1984). Does the concept of the person vary cross-culturally? Cambridge: Cambridge University Press.

[53] Triandis, H.C., Chan, D.K. S., Bhawuk, D.P.S., Iwao, S., \& Sinha, J.B.P. (1995). Multimethod probes of allocentrism and idiocentrism. International Journal Psychology, 30of (4), 461-480. DOI: $10.1080 / 00207599508246580$ 